\title{
Histopathological sample review and its impact on the risk of recurrence classification in patients with thyroid cancer
}

\author{
Fabián Pitoia $\mathbb{1}^{1}$
}

Received: 6 November 2020 / Accepted: 24 November 2020 / Published online: 5 January 2021

(c) Springer Science+Business Media, LLC, part of Springer Nature 2021

I read with great interest the recently published manuscript in Endocrine from Hescot et al. [1] in which they report similar results to what we had already reported in 2018 [2].

In this investigation, the authors showed that after comparing those pathological reports which had a second-opinion diagnosis, these histopathological modifications led to changes in the ATA 2015 risk stratification classification in $31 \%$ of patients. In our investigation, after reviewing historical pathological reports, this situation happened in $25 \%$ of our cases which led to a better refining of the prediction of the initial structural or excellent response to treatment. We are happy that our idea was similarly replicated in Europe with very comparable results.

\section{Compliance with ethical standards}

Conflict of interest The author declares no conflict of interest.

Publisher's note Springer Nature remains neutral with regard to jurisdictional claims in published maps and institutional affiliations.

\section{References}

1. S. Hescot, H. Sheikh-Alard, M. Kordahi, et al. Impact of expert review of histological diagnosis of papillary and follicular thyroid cancer. Endocrine (2020). https://doi.org/10.1007/s12020-020-02531-x

2. F. Pitoia, F. Jerkovich, C. Urciuoli, F. Falcón, A.P. Lima, Impact of historic histopathologic sample review on the risk of recurrence in patients with differentiated thyroid cancer. Arch. Endocrinol. Metab. 62 (2), 157-163 (2018). https://doi.org/10.20945/2359-3997000000020

Fabián Pitoia

fpitoia@intramed.net

1 Division of Endocrinology, Hospital de Clínicas, University of Buenos Aires, Buenos Aires, Argentina 